Pacific Journal of Mathematics

NONOSCILLATORY SOLUTIONS OF SECOND ORDER
NONLINEAR DIFFERENTIAL EQUATING 


\title{
NONOSCILLATORY SOLUTIONS OF SECOND ORDER NONLINEAR DIFFERENTIAL EQUATIONS
}

\author{
LYNN H. ERBE
}

We consider here a generalization of the equation

$$
x^{\prime \prime}+a(t) x^{2 n+1}=0
$$

where $a(t)$ is a continuous non-negative function on $[0,+\infty)$ and $n \geqq 0$ is an integer. Necessary and sufficient conditions are given for the existence of

(1) a bounded nonoscillatory solution with prescribed limit at $\infty$;

(2) a nonoscillatory solution whose derivative has a positive limit at $\infty$.

Specifically, we are concerned with the asymptotic behavior of the solutions of the following second order nonlinear differential equation :

$$
x^{\prime \prime}+f(t, x) g\left(x^{\prime}\right)=0 \text {. }
$$

We shall assume the following conditions hold:

$$
f(t, x), g\left(x^{\prime}\right) \text {, and the partial derivative function }
$$

$\left(A_{0}\right) \quad f_{x}(t, x)$ are all continuous for $t \geqq 0, x^{\prime} \geqq 0$, and

$$
|x|<+\infty \text {. }
$$

$$
f(t, 0)=0, t \geqq 0 .
$$

$\left(A_{2}\right) \quad f_{x}(t, x) \geqq 0$ and is nondecreasing in $x$ for $t \geqq 0$ and $x \geqq 0$.

$$
g\left(x^{\prime}\right)>0 \text { for all } x^{\prime} \geqq 0 \text {. }
$$

As a special case we have the equation

$$
x^{\prime \prime}+a(t) x^{2 n+1}=0, n \geqq 0,
$$

in which $a(t) \geqq 0$ for $t \geqq 0$ and $g\left(x^{\prime}\right)=1$ for all $x^{\prime}$. Oscillatory and nonoscillatory properties of (2) for the case $n \geq 1$ were investigated by Atkinson in [1], Moore and Nehari in [5], and Utz in [9]. Generalizations of equation (2) have been considered by Waltman in [7] and [8], Nehari in [6], Wong in [10], and Macki and Wong in [4].

We shall study equation (1) by considering the equation

$$
x^{\prime \prime}+f_{x}(t ; \alpha) x=0,
$$

where $\alpha$ is some real constant depending on solutions of (1). To do this we shall need to establish several lemmas concerning the equation 


$$
x^{\prime \prime}+p(t) x=0,
$$

where $p(t)$ is continuous and satisfies $p(t) \geqq 0$ for $t \geqq 0$.

LEMMA 1.1. Let $[a, b]$ be a compact interval of the reals and suppose there exists a $\beta(t) \in C^{(2)}[a, b]$ satisfying

$$
\beta(t)>0, \quad \beta^{\prime \prime}(t)+p(t) \beta(t) \leqq 0, \quad t \in[a, b] .
$$

Then $[a, b]$ is an interval of disconjugacy for equation (4). That is, no nontrival solution of (4) has more than one zero on $[a, b]$.

Proof. If the conclusion is false, then there is a solution $y(t)$ of (4) satisfying $y\left(t_{1}\right)=y\left(t_{2}\right)=0$ and $y(t)>0$ on $\left(t_{1}, t_{2}\right)$, where $a \leqq$ $t_{1}<t_{2} \leqq b$. It follows that there is a $k>0$ such that $k y(t) \leqq \beta(t)$ on $\left[t_{1}, t_{2}\right]$ and $k y\left(t_{0}\right)=\beta\left(t_{0}\right)$ for some $t_{1}<t_{0}<t_{2}$. Therefore, $k y^{\prime}\left(t_{0}\right)=$ $\beta^{\prime}\left(t_{0}\right)$ and for $t_{0} \leqq t \leqq t_{2}$ we have

$$
k y^{\prime}(t)-\beta^{\prime}(t) \geqq \int_{t_{0}}^{t}-p(s)\{k y(s)-\beta(s)\} d s \geqq 0 \text {. }
$$

Hence,

$$
k y\left(t_{2}\right)-\beta\left(t_{2}\right)=\int_{t_{0}}^{t_{2}}\left(k y^{\prime}(s)-\beta^{\prime}(s)\right) d s \geqq 0,
$$

which is a contradiction.

REMARK. If there exists an $\alpha(t) \in C^{(2)}[a, b]$ satisfying

$$
\alpha(t)<0, \quad \alpha^{\prime \prime}(t)+p(t) \alpha(t) \geqq 0, \quad t \in[a, b],
$$

then the conclusion of the lemma again holds. (Set $\beta(t)=-\alpha(t)$, $t \in[a, b]$.

Lemma 1.1 is closely related to a theorem of Wintner (see Hartman [2], p. 362, Th. 7.2) and could be obtained directly by setting $z=\beta^{\prime} / \beta$. Also, a function $\beta(t) \in C^{(2)}[a, b]$ satisfying $\beta^{\prime \prime}(t)+p(t) \beta(t) \leqq 0$ on $[a, b]$ is just a special case of an upper solution, as defined by Jackson in [3] for general nonlinear second order differential equations. Likewise $\alpha(t) \in C^{(2)}[a, b]$ satisfying $\alpha^{\prime \prime}(t)+p(t) \alpha(t) \geqq 0$ on $[a, b]$ is a special case of a lower solution.

LEMmA 1.2. Let $\alpha(t), \quad \beta(t) \in C^{(2)} \quad[a, b]$ and satisfy $\alpha^{\prime \prime}(t)+$ $p(t) \alpha(t) \geqq 0, \beta^{\prime \prime}(t)+p(t) \beta(t) \leqq 0$, and $0<\alpha(t) \leqq \beta(t)$ on $[a, b]$. Then for any $c$, $d$ with $\alpha(a) \leqq c \leqq \beta(a), \alpha(b) \leqq d \leqq \beta(b)$, there is a unique solution $z(t)$ of (4) satisfying $z(a)=c, z(b)=d$, and $\alpha(t) \leqq z(t) \leqq \beta(t)$ on $[a, b]$. 
Proof. By Lemma 1.1, $[a, b]$ is an interval of disconjugacy for equation (4) so that the $B V P$

$$
x^{\prime \prime}+p(t) x=0, \quad x(a)=c, \quad x(b)=d
$$

has a unique solution $z(t)$ (see for example [2], p. 351). Since $z(t)$ cannot have more than one zero on $[a, b]$ and since initial value problems for (4) have unique solutions, it follows that $z(t)>0$ on $[a, b]$. If the conclusion of the lemma is false, then assume, to be specific, that $z\left(t_{1}\right)-\beta\left(t_{1}\right)=z\left(t_{2}\right)-\beta\left(t_{2}\right)=0$ and $z(t)>\beta(t)$ on $\left(t_{1}, t_{2}\right)$, where $a \leqq t_{1}<t_{2} \leqq b$. As in Lemma 1.1, there is a $k>0, k<1$, such that $0<k z(t) \leqq \beta(t)$ on $\left[t_{1}, t_{2}\right]$, and $k z\left(t_{0}\right)=\beta\left(t_{0}\right), k z^{\prime}\left(t_{0}\right)=\beta^{\prime}\left(t_{0}\right)$ for some $t_{1}<t_{0}<t_{2}$. Since $k z\left(t_{2}\right)<z\left(t_{2}\right)=\beta\left(t_{2}\right)$, this leads to a contradiction as in Lemma 1.1. Hence, $z(t) \leqq \beta(t)$ on $[a, b]$. A similar argument shows that $z(t) \geqq \alpha(t)$ on $[a, b]$ and this proves the lemma.

LEMmA 1.3. Let $\alpha(t), \beta(t) \in C^{(2)}[a,+\infty)$ with $\alpha^{\prime \prime}(t)+p(t) \alpha(t) \geqq 0$, $\beta^{\prime \prime}(t)+p(t) \beta(t) \leqq 0$, and $0<\alpha(t) \leqq \beta(t)$ on $[a,+\infty)$. Then for any $\alpha(a) \leqq c \leqq \beta(a)$ there is a solution $y(t) \in C^{(2)}[a,+\infty)$ of (4) satisfying $y(a)=c$ and $\alpha(t) \leqq y(t) \leqq \beta(t)$ on $[a,+\infty)$.

Proof. By Lemma 1.2 for each $n \geqq 1$ there is a solution $y_{n}(t) \in C^{(2)}$ $[a, a+n]$ of (4) satisfying $y_{n}(a)=c$ and $\alpha(t) \leqq y_{n}(t) \leqq \beta(t)$ on $[a, a+n]$. Therefore, for each $N \geqq 1\left|y_{n}(t)\right|$ and hence $\left|y_{n}^{\prime \prime}(t)\right|$ are uniformly bounded on $[a, a+N]$ for all $n=N$. Since $y_{n}^{\prime}(t)=y_{n}^{\prime}(a)+\int_{a}^{t} y_{n}^{\prime \prime}$, the $\left|y_{n}^{\prime}(t)\right|$ are likewise bounded on $[a, a+N]$, uniformly for $n \geqq N$. Now consider the sequence $\left\{y_{n}(t)\right\}_{n=1}^{\infty}$. By the Ascoli-Arzela Theorem there is a subsequence $\left\{y_{n}^{1}(t)\right\}_{n=1}^{\infty}$ converging to a solution $z_{1}(t)$ of (4) on $[a, a+1]$. Inductively, for each $k \geqq 2$ we obtain a subsequence $\left\{y_{n}^{k}(t)\right\}_{n=1}^{\infty}$ of $\left\{y_{n}^{k-1}(t)\right\}_{n=1}^{\infty}$ which converges to a solution $z_{\kappa}(t)$ of (4) on $[a, a+k]$. Therefore, the diagonal sequence $\left\{y_{k}^{k}(t)\right\}_{k=1}^{\infty}$ converges uniformly on each compact subinterval of $[a,+\infty)$. That is,

$$
z(t)=\lim _{k \rightarrow \infty} y_{k}^{k}(t), \quad t \in[a,+\infty),
$$

is the desired solution.

2. After these preliminary lemmas, we are now in a position to establish necessary and sufficient conditions for the existence of certain types of solutions of (1).

Theorem 2.1. Assume $A_{0}-A_{3}$ hold and let $\alpha_{0}>0$. Then the following statements are equivalent:

(a) For each $0<\alpha<\alpha_{0}$ there is a solution $u_{\alpha}(t)$ of (1) satisfying $\lim _{t \rightarrow \infty} u_{\alpha}(t)=\alpha$. 
(b) $\int^{\infty} t f_{y}(t, \alpha) d t<+\infty$ for $0<\alpha<\alpha_{0}$.

Proof. (a) implies (b): Assume $\int^{\infty} t f_{y}\left(t, \alpha_{1}\right) d t=+\infty$ for some $0<\alpha_{1}<\alpha_{0}$ and let $\alpha_{1}<\beta<\alpha_{0}$. Let $u_{\beta}(t)$ be the corresponding solution of (1) with $\lim _{t \rightarrow \infty} u_{\beta}(t)=\beta$. Let $\delta>0$ be such that $\alpha_{1}+\delta<\beta$ and let $T \geqq 0$ be such that $t \geqq T$ implies $u_{\beta}(t) \geqq \alpha_{1}+\delta$. Then for $t \geqq T$

$$
u_{\beta}^{\prime \prime}=-f\left(t, u_{\beta}\right) g\left(u_{\beta}^{\prime}\right) \leqq 0
$$

so that $u_{\beta}^{\prime}$ decreases to a limit, and this limit clearly must be zero. Therefore, $u_{\beta}(t) \leqq \beta$ for $t \geqq T$ so that applying the Mean Value Theorem we get

$$
\begin{aligned}
f_{y}\left(t, \alpha_{1}\right) & \leqq \frac{f\left(t, u_{\beta}(t)\right)-f\left(t, \alpha_{1}\right)}{u_{\beta}(t)-\alpha_{1}} \leqq \frac{f\left(t, u_{\beta}(t)\right)}{u_{\beta}(t)-\alpha_{1}} \\
& \leqq \frac{u_{\beta}(t)}{u_{\beta}(t)-\alpha_{1}} \frac{f\left(t, u_{\beta}(t)\right)}{u_{\beta}(t)} \leqq \frac{\beta}{\delta} \frac{f\left(t, u_{\beta}(t)\right)}{u_{\beta}(t)},
\end{aligned}
$$

for $t \geqq T$. Since $\lim _{t \rightarrow \infty} u_{\beta}^{\prime}(t)=0$, there is a $T_{1} \geqq T$ such that $t \geqq T_{1}$ implies $g\left(u_{\beta}^{\prime}(t)\right) \geqq g(0) / 2>0$. Hence, for $t \geqq T_{1}$ we have

$$
u_{\beta}^{\prime \prime}(t)=-f\left(t, u_{\beta}(t)\right) g\left(u_{\beta}^{\prime}(t)\right) \leqq-k f_{y}\left(t, \alpha_{1}\right) u_{\beta}(t),
$$

where $k=g(0)(\delta / 2 \beta)$. Also, $\alpha_{1}^{\prime \prime}=0 \geqq-k f_{y}\left(t, \alpha_{1}\right) \alpha_{1}$. Therefore, by Lemma 1.3 there is a solution $z(t)$ of the equation

$$
x^{\prime \prime}+k f_{y}\left(t, \alpha_{1}\right) x=0
$$

satisfying $\alpha_{1} \leqq z(t) \leqq u_{\beta}(t)$ on $\left[T_{1},+\infty\right)$. Let $w(t)=z(t) \int_{T_{1}}^{t} d s /(z(s))^{2}$ for $t \geqq T_{1}$. Then $w(t)$ is a solution of $(5)$. Since $z^{\prime \prime}(t) \leqq 0$ for $t \geqq T_{1}$, we see that

$$
w^{\prime \prime}(t)=z^{\prime \prime}(t) \int_{T_{1}}^{t} d s /(z(s))^{2} \leqq 0
$$

for $t \geqq T_{1}$ and hence $w^{\prime}(t)$ decreases to a finite nonnegative limit. In fact, we have

$$
w^{\prime}(t)=1 / z(t)+z^{\prime}(t) \int_{T_{1}}^{t} d s /(z(s))^{2} \geqq 1 / z(t) \geqq 1 / \beta
$$

for $t \geqq T_{1}$. Hence, for sufficiently large $t$, say $t \geqq T_{0} \geqq T_{1}$, we have $w(t) \geqq t / 2 \beta$. Therefore, for $t \geqq T_{0}$ we have

$$
\begin{gathered}
w^{\prime}(t)-w^{\prime}\left(T_{0}\right)=-k \int_{T_{0}}^{t} f_{y}\left(s, \alpha_{1}\right) w(s) d s \\
\leqq(-k / 2 \beta) \int_{T_{0}}^{t} s f_{y}\left(s, \alpha_{1}\right) d s \leqq 0 .
\end{gathered}
$$


Therefore,

$$
w^{\prime}\left(T_{0}\right) \geqq w^{\prime}(t)+(k / 2 \beta) \int_{T_{0}}^{t} s f_{y}\left(s, \alpha_{1}\right) d s
$$

for $t \geqq T_{0}$, so that

$$
\int_{T_{0}}^{\infty} s f_{y}\left(s, \alpha_{1}\right) d s<+\infty,
$$

which is the desired contradiction.

Conversely, let $0<\alpha<\alpha_{0}$ be given and let

$$
M=\max \left\{g\left(x^{\prime}\right): 0 \leqq x^{\prime} \leqq \alpha\right\} .
$$

Let $T \geqq 0$ be such that

$$
\int_{T}^{\infty}(s-T) f_{y}(s, \alpha) d s<1 / M \text { and } \int_{T}^{\infty} f_{y}(s, \alpha) d s<1 / M .
$$

We shall now define a sequence of functions on $[T,+\infty)$ in the following manner :

Let $y_{0}(t)=\alpha, t \geqq T$. Now for $t \geqq T$

$$
0 \leqq \int_{t}^{\infty}(s-t) f(s, \alpha) g(0) d s \leqq \alpha \int_{t}^{\infty}(s-t) f_{y}(s, \alpha) g(0) d s \leqq \alpha,
$$

so that defining $y_{1}(t)=\alpha-\int_{t}^{\infty}(s-t) f(s, \alpha) g(0) d s, t \geqq T$, we have $0 \leqq y_{1}(t) \leqq \alpha$. Differentiating $y_{1}(t)$ we have

$$
0 \leqq y_{1}^{\prime}(t)=\int_{t}^{\infty} f(s, \alpha) g(0) d s \leqq M \alpha \int_{t}^{\infty} f_{y}(s, \alpha) d s<\alpha .
$$

Proceeding inductively, we define for all $k \geqq 1$

$$
y_{k+1}(t)=\alpha-\int_{t}^{\infty}(s-t) f\left(s, y_{k}(s)\right) g\left(y_{k}^{\prime}(s)\right) d s, \quad t \geqq T,
$$

and obtain $0 \leqq y_{k}(t), y_{k}^{\prime}(t) \leqq \alpha$ for all $k \geqq 1$. It follows that the sequences $y_{k}(t), y_{k}^{\prime}(t)$, and $y_{k}^{\prime \prime}(t)$ are uniformly bounded on $[T, T+n]$ for all $n \geqq 1$. The Ascoli-Arzela Theorem and a diagonalization argument yields a subsequence which converges, uniformly on compact subsets of $[T,+\infty)$, to a solution $u_{\alpha}(t)$ of (1). Obviously, $\lim _{t \rightarrow \infty} u_{\alpha}(t)=\alpha$. This completes the proof of the theorem.

REMARK. If $f(t, x)=-f(t,-x)$ and $g\left(x^{\prime}\right)>0$ and is continuous for $\left|x^{\prime}\right|<+\infty$, then we see that $\int^{\infty} t f_{y}(t, \alpha) d t<+\infty$ for $0<|\alpha|<\alpha_{0}$ if and only if for each $0<|\alpha|<\alpha_{0}$ there is a solution $u_{\alpha}(t)$ of (1) with $\lim _{t \rightarrow \infty} u_{\alpha}(t)=\alpha$. 
Corollary 2.2. $\int^{\infty} t f_{y}(t, \alpha) d t<+\infty$ for all $\alpha>0$ if and only if there is a solution $u_{\alpha}(t)$ of $(1)$ with $\lim _{t \rightarrow \infty} u_{\alpha}(t)=\alpha$ for all $\alpha>0$.

CoROLlary 2.3. If $f(t, x)=\sum_{i=0}^{n} a_{i}(t) x^{2 i+1}$ where the $a_{i}(t)$ are continuous nonnegative functions for $t \geqq 0$, then the following statements are equivalent:

(a) There is a solution $u_{\alpha}(t)$ of (1) with $\lim _{t \rightarrow \infty} u_{\alpha}(t)=\alpha$ for all $\alpha \neq 0$.

(b) $\sum_{i=0}^{n} \int t a_{i}(t) d t<+\infty$.

As examples of equations to which Theorem 2.1 applies but which do not belong to any of the classes of equations considered in references [1], [4] through [8], we have

$$
\begin{gathered}
x^{\prime \prime}+x\left(\exp \left(t\left(x-\alpha_{0}\right)\right)\right)\left(1+x^{\prime}\right)=0 \\
x^{\prime \prime}+x\left(\exp \left(t\left(x^{2}-\alpha_{0}^{2}\right)+c x^{\prime}\right)\right)\left(1+\left(x^{\prime}\right)^{2}\right)=0,
\end{gathered}
$$

where $c$ is an arbitrary real number. Then for $0<\alpha<\alpha_{0}$ there is a solution $u_{\alpha}(t)$ of (6) with $\lim _{t \rightarrow \infty} u_{\alpha}(t)=\alpha$, and for $0<|\alpha|<\alpha_{0}$ there is a solution $y_{\alpha}(t)$ of (7) with $\lim _{t \rightarrow \infty} y_{\alpha}(t)=\alpha$.

3. In [5] it is shown that equation (2) has solutions for which

$$
\lim _{t \rightarrow \infty} \frac{y(t)}{t}=\alpha>0
$$

if and only if

$$
\int^{\infty} t^{2 n+1} a(t) d t<+\infty .
$$

In this final section we will show that an analogous result is true for equation (1) provided $f(t, x)$ satisfies the following additional condition.

$\left(A_{4}\right)$ There exist real numbers $c>0$ and $\lambda>0$ such that $\lim _{x \rightarrow \infty} \inf \frac{f(t, x)}{x f_{x}(t, c x)} \geqq \lambda>0$, for all sufficiently large $t$.

Note that in the case of equation (2) $c$ and $\lambda$ may be any positive real numbers with $\lambda c^{2 n} \leqq 1 /(2 n+1)$. We first establish the following lemma.

Lemma 3.1. Assume conditions $A_{0}-A_{3}$ hold and let there exist a real number $\beta>0$ with

$$
\int^{\infty} t f_{y}(t, \beta t) d t<+\infty \text {. }
$$


Then there exist solutions to (1), say $y(t)$, such that $\lim _{t \rightarrow \infty} y(t) / t$ exists and is positive.

Proof. Let $T>0$ be such that

$$
\int_{T}^{\infty} t f_{y}(t, \beta t) d t<1 / 2 M
$$

where $M=\max \left\{g\left(x^{\prime}\right): 0 \leqq x^{\prime} \leqq \beta\right\}$. We define a solution of (1) by

$$
u(T)=0, \quad u^{\prime}(T)=\beta,
$$

and we assert that the solution satisfies $u^{\prime}(t) \geqq \beta / 2$ for $t \geqq T$. Assume, on the contrary, that there is a $\delta>0, \beta / 2>\delta>0$, and a $t_{1}>T$ with $u^{\prime}\left(t_{1}\right)=\delta$ and $u(t)>0$ on $\left(T, t_{1}\right]$. Then for $T \leqq t \leqq t_{1}$ we have

$$
u^{\prime}(T)=u^{\prime}(t)+\int_{T}^{t} f(s, u(s)) g\left(u^{\prime}(s)\right) d s .
$$

Since $u^{\prime \prime}(t) \leqq 0$ on $\left(T, t_{1}\right]$ and since $u(t)$ is concave it follows that

$$
\begin{aligned}
& u^{\prime}(t) \leqq \beta \quad \text { on }\left(T, t_{1}\right) \quad \text { and } \\
& u(t) \leqq \beta(t-T) \text { on }\left(T, t_{1}\right) .
\end{aligned}
$$

Applying the Mean Value Theorem in (8) we have

$$
\begin{aligned}
\beta= & u^{\prime}(T)<u^{\prime}(t)+M \beta \int_{T}^{t} s f_{y}(s, \beta(s-T)) d s \\
& \leqq u^{\prime}(t)+M \beta \int_{T}^{t} s f_{y}(s, \beta s) d s<u^{\prime}(t)+\beta / 2 .
\end{aligned}
$$

Hence, $u^{\prime}\left(t_{1}\right)>\beta / 2$, a contradiction. Therefore, $u^{\prime}(t) \geqq \beta / 2$ on $[T,+\infty)$ and hence $\lim _{t \rightarrow \infty} u^{\prime}(t)$ exists and is positive which implies that $\lim _{t \rightarrow \infty} u(t) / t$ exists and is positive.

Theorem 3.2. Assume conditions $\left(A_{0}\right)-\left(A_{4}\right)$ hold. Then (1) has solutions, say $y(t)$, such that $\lim _{t \rightarrow \infty} y(t) / t$ exists and is positive if and only if

$$
\int^{\infty} t f_{y}(t, \beta t) d t<+\infty \text { for some } \beta_{.}>0 .
$$

Proof. Let $\alpha>0$ and let $y(t)$ be a solution of (1) with

$$
\lim _{t \rightarrow \infty} \frac{y(t)}{t}=\alpha \text {. }
$$

Let $T \geqq 0$ be such that $t \geqq T$ implies $y(t) \geqq \alpha t / 2$. Let

$$
m_{0}=\min \left\{g\left(x^{\prime}\right): 0 \leqq x^{\prime} \leqq y^{\prime}(T)\right. \text {. }
$$


By condition $\left(A_{4}\right)$ there is a $T_{1} \geqq T$ such that $t \geqq T_{1}$ implies

$$
f(t, y(t)) \geqq \lambda y(t) f_{y}(t, c \alpha t / 2) \geqq(k t) f_{y}(t, c \alpha t / 2),
$$

where $k=\lambda \alpha / 2$. Since $0<y^{\prime}(t) \leqq y^{\prime}(T)$ for $t \geqq T$ we have

$$
f(t, y(t)) g\left(y^{\prime}(t)\right) \geqq\left(m_{0} k t\right) f_{y}(t, c \alpha t / 2), \quad t \geqq T_{1} \text {. }
$$

Therefore,

$$
\begin{aligned}
y^{\prime}\left(T_{1}\right) & =y^{\prime}(t)+\int_{T_{1}}^{t} f(s, y(s)) g\left(y^{\prime}(s)\right) d s \\
& \geqq y^{\prime}(t)+\int_{T_{1}}^{t}\left(m_{0} k s\right) f_{y}(s, c \alpha s / 2) d s .
\end{aligned}
$$

Since $\lim _{t \rightarrow \infty} y^{\prime}(t) \geqq 0$, this implies that

$$
\int_{T_{1}}^{\infty} s f_{y}(s, c \alpha s / 2) d s<+\infty,
$$

and this proves the theorem.

As a simple example of an equation to which the previous theorem applies but which is not considered in references [1], [4] through [8], we have

$$
x^{\prime \prime}+x^{2}(\exp (x-\beta t))\left(1+x^{\prime}\right)=0,
$$

where $\beta>0$. Condition $\left(A_{4}\right)$ holds for any $0<c<1$ and any $\lambda>0$.

The author wishes to thank Professor Lloyd Jackson and the referee for several helpful comments and suggestions.

\section{REFERENCES}

1. F. V. Atkinson, On second order nonlinear oscillations, Pacific J. Math. 5 (1955), 643-647.

2. P. Hartman, Ordinary differential equations, Wiley, 1964.

3. L. K. Jackson, Subfunctions and second order differential inequalities, Advances in Math., Academic Press (to appear).

4. J. W. Macki and J. S. W. Wong, Oscillation of solutions to second order nonlinear differential equations, Pacificic J. Math. 18 (1968) (to appear)

5. R. A. Moore and Z. Nehari, Nonoscillation theorems for a class of nonlinear differential equations, Trans. Amer. Math. Soc. 92-93 (1959), 30-52.

6. Z. Nehari, On a class of nonlinear second order differential equations, Trans. Amer. Math. Soc. 94-95 (1960), 101-123.

7. P. Waltman, Oscillation of solutions of a nonlinear equation, SIAM Review 5 (1963), 128-130.

8. Some properties of solution of $u^{\prime \prime}+a(t) f(u)=0$, Monat. Math. (1963-64), 50-54.

9. W. R. Utz, Properties of solutions of $u^{\prime \prime}+g(t) u^{2 n-1}=0$, Monat. Math. (1961-62), 55-60. 
10. J. S. W. Wong, A note on second order nonlinear oscillation, SIAM Review 10 (1968), 88-91.

Received June 19, 1968. This research was supported by a NASA Traineeship at the University of Nebraska.

The University of Nebraska

LINCOLN, NEBRASKA, AND

The University OF Alberta

EDMONTON, Alberta 



\section{PACIFIC JOURNAL OF MATHEMATICS}

\section{EDITORS}

H. ROYDEN

Stanford University

Stanford, California

R. R Phelps

University of Washington

Seattle, Washington 98105
J. DUGUNDJI

Department of Mathematics

University of Southern California

Los Angeles, California 90007

RICHARD ARENS

University of California

Los Angeles, California 90024

\section{ASSOCIATE EDITORS}
E. F. BECKENBACH
B. H. NeumanN
F. WOLF
K. YosidA

\section{SUPPORTING INSTITUTIONS}

UNIVERSITY OF BRITISH COLUMBIA

CALIFORNIA INSTITUTE OF TECHNOLOGY

UNIVERSITY OF CALIFORNIA

MONTANA STATE UNIVERSITY

UNIVERSITY OF NEVADA

NEW MEXICO STATE UNIVERSITY

OREGON STATE UNIVERSITY

UNIVERSITY OF OREGON

OSAKA UNIVERSITY

UNIVERSITY OF SOUTHERN CALIFORNIA
STANFORD UNIVERSITY

UNIVERSITY OF TOKYO

UNIVERSITY OF UTAH

WASHINGTON STATE UNIVERSITY

UNIVERSITY OF WASHINGTON

AMERICAN MATHEMATICAL SOCIETY CHEVRON RESEARCH CORPORATION TRW SYSTEMS

NAVAL WEAPONS CENTER 


\section{Pacific Journal of Mathematics

Vol. 28, No. $1 \quad$ March, 1969

Patrick Robert Ahern, On the geometry of the unit ball in the space of real annihilating measures .............................. 1

Kirby Alan Baker, Equational classes of modular lattices ............. 9

E. F. Beckenbach and Gerald Andrew Hutchison, Meromorphic minimal surfaces ......................................... 17

Tae Ho Choe, Intrinsic topologies in a topological lattice ..............

John Bligh Conway, A theorem on sequential convergence of measures and

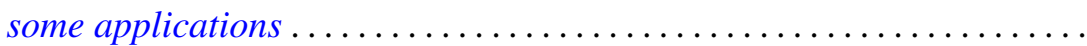

Roger Cuppens, On the decomposition of infinitely divisible probability laws without normal factor.

Lynn Harry Erbe, Nonoscillatory solutions of second order nonlinear

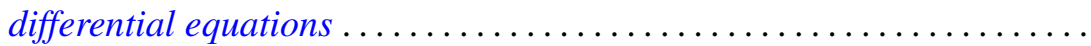

Burton I. Fein, The Schur index for projective representations of finite

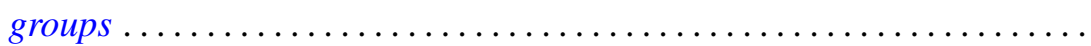

Stanley P. Gudder, A note on proposition observables............... 101

Kenneth Kapp, On Croisot's theory of decompositions ............... 105

Robert P. Kaufman, Gap series and an example to Malliavin's theorem . . . 117

E. J. McShane, Robert Breckenridge Warfield, Jr. and V. M. Warfield,

Invariant extensions of linear functionals, with applications to measures and stochastic processes ................

Marvin Victor Mielke, Rearrangement of spherical modifications ...

Akio Osada, On unicity of capacity functions ..............

Donald Steven Passman, Some 5/2 transitive permutation groups ...

Harold L. Peterson, Jr., Regular and irregular measures on groups and dyadic spaces...

Habib Salehi, On interpolation of $q$-variate stationary stochastic processes...

Michael Samuel Skaff, Vector valued Orlicz spaces generalized

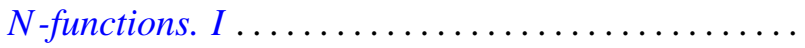

A. J. Ward, On $H$-equivalence of uniformities. II...........

Thomas Paul Whaley, Algebras satisfying the descending chain condition for subalgebras...

G. K. White, On subgroups of fixed index

Martin Michael Zuckerman, A unifying condition for implications among the axioms of choice for finite sets ................. 